\title{
Supplemental Information: Biogeochemistry of the Antrim Shale Natural Gas Reservoir
}

Brooke Stemple ${ }^{1,2}$, Kara Tinker ${ }^{3,4}$, Preom Sarkar $^{2,3}$, Josh Miller ${ }^{2,3}$, Djuna Gulliver ${ }^{3 *}$, Kyle Bibby $^{1 *}$

${ }^{1}$ Department of Civil and Environmental Engineering and Earth Sciences, University of Notre Dame, Notre Dame, Indiana, 46556 USA, ${ }^{2}$ Oakridge Institute for Science and Education, Oak Ridge, Tennessee, 37830, USA ${ }^{3}$ National Energy Technology Laboratory (NETL), Pittsburgh, Pennsylvania, 15236, USA, ${ }^{4}$ Leidos Research Support Team, Pittsburgh, Pennsylvania, 15236, USA

*Correspondence: Kyle Bibby (kbibby@nd.edu); Djuna Gulliver (djuna.gulliver@netl.doe.gov)

Number of figures: 2

Number of tables: 2

Number of pages: 6

Supplementary figures showing the $\log _{10} 16 \mathrm{~S}$ copies/L for produced water samples from Antrim Shale wells and a non-metric multidimensional scaling (NMDS) plot of produced water samples showing statically significant $(\mathrm{p} \leq 0.05)$ geochemical parameters; Supplementary tables of Antrim Shale measured cations and anions. 


\section{Figures}

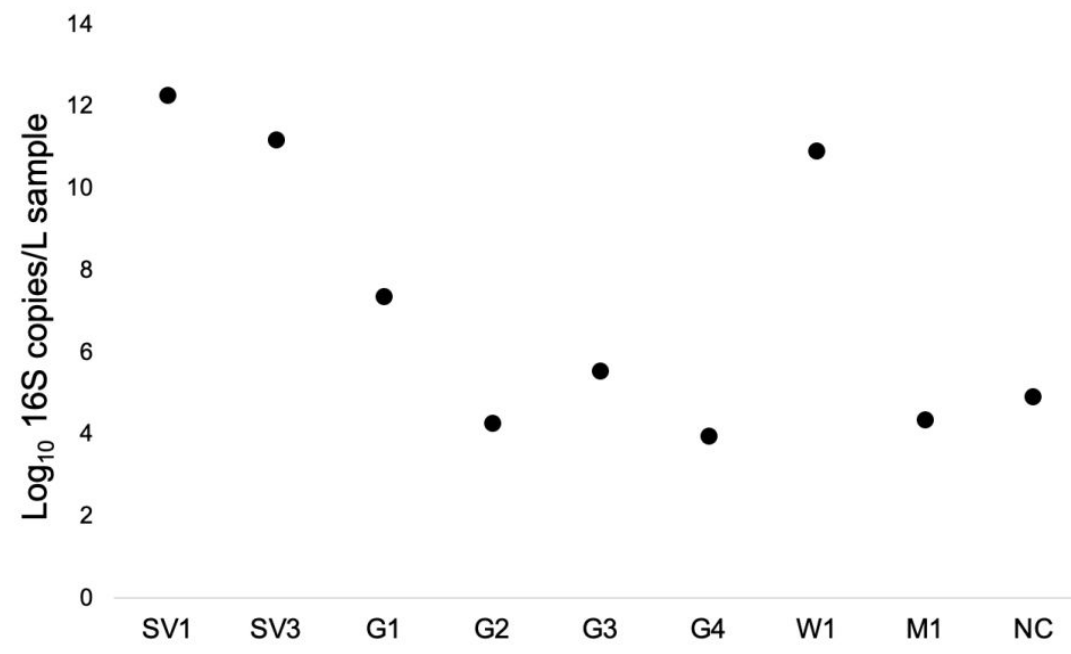

Figure S1. $\log _{10} 16 \mathrm{~S}$ copies/L sample for Antrim Shale wells quantified by MIC qPCR. SV2 sample not shown as DNA could not be quantified due to low DNA yield. 


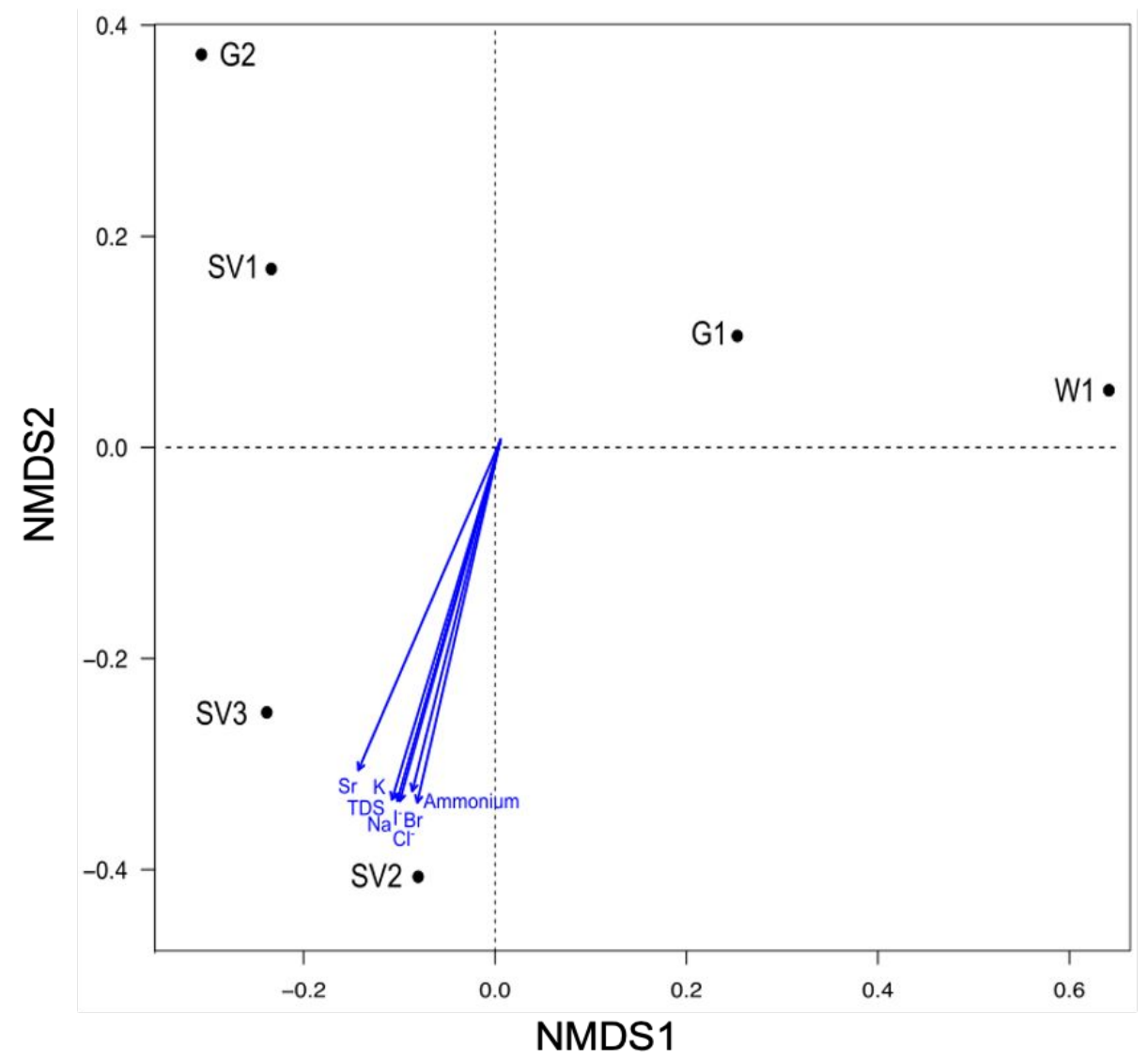

Figure S2. Non-metric multidimensional scaling (NMDS) plot of produced water samples with a stress value of 0.15 . This plot was constructed using Bray-Curtis distances. 
$\underline{\text { Tables }}$

Table S1: Antrim Shale measured cations. All measurements are reported in $\mathrm{mg} / \mathrm{L}$.

Antrim Lithium Sodium Ammonium Potassium Magnesium Calcium Strontium Barium Well ID

\begin{tabular}{|c|c|c|c|c|c|c|c|c|}
\hline G3 & 2.02 & 35176 & 83.8 & 233 & 953 & 5409 & 43.15 & ND \\
\hline $\mathrm{G} 1$ & 6.88 & 31541 & 62.36 & 179 & 402 & 456 & 36.08 & 25.87 \\
\hline G2 & 2.39 & 32277 & 33.9 & 197 & 417 & 1893 & 38.7 & 47.34 \\
\hline G4 & 6.51 & 29824 & 65.2 & 180 & 397 & 932 & 34.6 & 8.13 \\
\hline M1 & 6.72 & 31466 & 64 & 178 & 376 & 378 & 36.7 & 32.37 \\
\hline SV1 & 2.91 & 39432 & 31 & 221 & 825 & 1913 & 46.72 & 14.12 \\
\hline SV2 & 0.54 & 2828 & 9.84 & 13.01 & 28.11 & 15.2 & 1.2 & 1.15 \\
\hline SV3 & 0.48 & 2603 & 7.1 & 11.8 & 23.48 & 28.83 & 1.33 & 2.53 \\
\hline W1 & 0.4 & 2227 & 8.15 & 9.8 & 23.9 & 30.4 & 1.25 & 1.76 \\
\hline
\end{tabular}


Table S2. Antrim Shale measured anions. All measurements are reported in $\mathrm{mg} / \mathrm{L}$.

\begin{tabular}{|c|c|c|c|c|c|c|c|c|}
\hline $\begin{array}{l}\text { Antrim } \\
\text { Well ID }\end{array}$ & Fluoride & Acetate & Propionate & Chloride & Bromide & Nitrate & Succinate & Sulfate \\
\hline G1 & 0.57 & 13.42 & 4.48 & 13923.12 & 39.73 & 0.07 & 1.92 & 0.04 \\
\hline G2 & 0.81 & 6.55 & 4.02 & 71312.24 & 258.47 & 0.06 & 1.82 & 532.56 \\
\hline G3 & ND & 7.69 & 4.40 & 59645.59 & 187.20 & ND & 1.89 & 0.12 \\
\hline G4 & ND & 7.06 & 4.58 & 54385.04 & 158.48 & 0.08 & 4.82 & 9.32 \\
\hline SV1 & 0.33 & 0.82 & 0.50 & 3591.37 & 5.88 & 0.12 & 0.19 & 0.06 \\
\hline SV2 & 0.52 & 0.742 & 0.50 & 2951.89 & 4.81 & 0.10 & 0.19 & 0.25 \\
\hline sv3 & 0.33 & 0.762 & 0.52 & 2622.05 & 4.42 & 0.10 & 0.18 & 0.03 \\
\hline M1 & 0.61 & 20.62 & 70.83 & 73445.77 & 197.29 & 0.09 & 1.83 & 0.14 \\
\hline W1 & 0.88 & 0.70 & 4.22 & 54859.61 & 133.12 & 0.07 & 9.24 & 0.31 \\
\hline $\mathrm{H}_{2} \mathrm{O}$ & 0.02 & 0.09 & 0.06 & ND & 0.26 & 0.17 & 0.03 & 0.05 \\
\hline
\end{tabular}




\begin{tabular}{|c|c|c|c|c|}
\hline $\begin{array}{l}\text { Antrim } \\
\text { Well ID }\end{array}$ & Oxalate & Phosphate & Thiosulfate & lodide \\
\hline G1 & 0.0 & ND & ND & 0.99 \\
\hline G2 & 0.03 & ND & 0.05 & 1.09 \\
\hline G3 & 0.06 & 0.11 & 0.03 & 1.25 \\
\hline G4 & 0.04 & ND & 0.02 & 0.89 \\
\hline SV1 & 0.05 & ND & ND & 1.14 \\
\hline SV2 & 0.04 & ND & 0.02 & 0.11 \\
\hline SV3 & 0.04 & ND & 0.02 & 1.04 \\
\hline M1 & 0.04 & ND & 0.02 & 1.04 \\
\hline W1 & 0.03 & ND & ND & 0.11 \\
\hline $\mathrm{H}_{2} \mathrm{O}$ Control & 0.04 & 0.22 & ND & ND \\
\hline
\end{tabular}

